Article

\title{
Evaluation of Structural and Mechanical Properties of Porous Artificial Bone Scaffolds Fabricated via Advanced TBA-Based Freeze-Gel Casting Technique
}

\author{
Tae-Rim Kim ${ }^{1,2}$, Min-Su Kim ${ }^{3}$, Tae Sik Goh ${ }^{4}$, Jung Sub Lee ${ }^{4}$, Yun Hak Kim ${ }^{5}$, \\ Seog-Young Yoon ${ }^{2, *(D)}$ and Chi-Seung Lee ${ }^{3,6,7, * \mathbb{D}}$ \\ 1 Pusan National University, University Research Park, Busan 49241, Korea; kimtaerim@pusan.ac.kr (T.-R.K.) \\ School of Materials Science Engineering, Pusan National University, Busan 46241, Korea \\ 3 Department of Biomedical Engineering, School of Medicine, Pusan National University, Busan 49241, Korea; \\ miiinsu93@gmail.com (M.-S.K.) \\ 4 Department of Orthopedic Surgery and Biomedical Research Institute, Pusan National University Hospital, \\ Busan 49241, Korea; taesikgoh@gmail.com (T.S.G.); jungsublee@pusan.ac.kr (J.S.L.) \\ 5 Department of Anatomy, School of Medicine, Pusan National University, Yangsan 50612, Korea, \\ yunhak10510@pusan.ac.kr \\ 6 Biomedical Research Institute, Pusan National University Hospital, Busan 49241, Korea \\ 7 Department of Convergence Medicine, School of Medicine, Pusan National University, Busan 49241, Korea \\ * Correspondence: syy3@pusan.ac.kr (S.-Y.Y.); victorich@pusan.ac.kr (C.-S.L.); Tel.: +82-51-510-3226 (S.-Y.Y.); \\ +82-51-240-6867 (C.-S.L.)
}

Received: 19 February 2019; Accepted: 8 May 2019; Published: 13 May 2019

check for updates

\begin{abstract}
Porous hydroxyapatite (HA) artificial bone scaffolds were prepared via the freeze-gel casting process in order to improve their mechanical strengths. As a porogen, various volumes of poly (methyl methacrylate) (PMMA) powders were added to obtain high porosity, such as in cancellous bone. After fabrication, the porous and mechanical properties of the scaffolds were examined. The HA60 scaffold, with a porosity over $80 \%$, had proper compressive strength and modulus and satisfied the range of properties of cancellous bone. Moreover, it was found that the investigated mechanical properties were affected by the scaffolds' porosity. However, a section was found where the compressive strength was high despite the increase in the porosity. Specifically, HA30 had a porosity of $62.9 \%$ and a compressive strength of $1.73 \mathrm{MPa}$, whereas the values for HA60 were $81.9 \%$ and 3.23 MPa, respectively. The results indicate that there are factors that can preserve the mechanical properties even if the porosity of the scaffold increases. Therefore, in this study, various parameters affecting the porous and mechanical properties of the scaffolds during the manufacturing process were analyzed. It is expected that the improvement in the mechanical properties of the artificial bone scaffold having a high porosity can be applied to tissue engineering.
\end{abstract}

Keywords: bone scaffold; mechanical property; porous property; porogen; hydroxyapatite

\section{Introduction}

The development and manufacturing of artificial bone scaffolds are among the major directions of tissue engineering [1-3]. Bone scaffolds have been used for a variety of reasons. Scaffolds were developed as empty matrices for adhesion and proliferation of migrating cells and are used for drug-delivery systems owing to their porous architecture [4-6]. In addition, they have been utilized for supporting cell structures $[7,8]$. Therefore, multiple factors, including the biocompatibility, bioactivity, and porous and mechanical properties, have been considered for the development of bone scaffolds. 
In particular, the porous properties, which are closely related to the structure and function of the scaffold, were considered to be the most important factor in manufacturing bone scaffolds [9,10]. On the other hand, stress shielding occurs owing to differences in the mechanical properties between bone scaffolds and the surrounding tissue [11,12]. Hence, it is also important that bone scaffolds be designed to have mechanical properties similar to those of cancellous bone.

Porous properties - such as porosity, pore-size distribution, and shape of the pores—are directly related to the function of porous scaffolds [13-17]. Woodard et al. [18] indicated that pores having a diameter of more than $300 \mu \mathrm{m}$ connect tissues such as blood vessels surrounding the bone defect, and pores $50 \mu \mathrm{m}$ in diameter are used for bone regeneration and are advantageous for expanding specific surfaces. Rustom et al. [19] fabricated two types of calcium phosphate scaffolds; one had both macropores and micropores and other had only macropores. It was shown that large interconnected macropores $(>300 \mu \mathrm{m})$ provide space for bone ingrowth, vascularization, and innervation, and that micropores $(<20 \mu \mathrm{m})$ improve the capillarity of bone scaffolds which increase the amount and the variety of cells drawn through the microporous network. Thus, scaffolds should have a distribution of pores ranging from several micrometers to several hundred micrometers. However, in general, as the pores in the material become diverse and increase in number, the mechanical stiffness and strength decrease, and the material becomes vulnerable to breakage [20]. Additionally, according to previous studies, the porosity and compressive strength are inversely proportional [21,22]. These studies in the literature showed result values of porosity and mechanical properties, and indicated that density and wall thickness were proportional to mechanical properties and inversely proportional to porosity. There is no clear explanation, however, for the factors affecting the relationship between the two characteristics. On the other hand, Pecqueux et al. [20] indicated that rather than microporosity, macroporosity affected compressive strength. Almirall et al. [23] showed that in spite of a high total porosity, a high ratio of microporosity to macroporosity can increase the compressive strength of porous scaffolds, even though several previous studies had suggested that a higher porosity corresponded to a lower compressive strength $[24,25]$. This shows that although it is difficult to fabricate the scaffolds with high porosity and proper mechanical properties similar to those of a cancellous bone, it can be overcome by developing a fabrication process technique that controls pore distribution.

Hence, studies on fabrication techniques of scaffolds having proper porous and mechanical properties have been continuously conducted. According to Yuan et al. [26], the method of fabricating bone scaffolds is divided into 3D printing and traditional methods. 3D printing techniques are classified with direct methods such as stereolithography (SLA), selective layer sintering (SLS), and ink-jet printing as well as indirect methods, for example, wax printing. A paper adopting the wax printing method was recently reported. Zhao and Liang [27] fabricated honeycomb porous bone scaffolds composed of chitosan/hydroxyapatite (CS/HA) composites with pores uniformly distributed using a wax mold that was printed on a three-dimensional (3D) printer. The scaffolds exhibited higher porosity and compressive strength than other porous CS/HA scaffolds manufactured via other production methods. The mechanical properties of the scaffolds varied for different fabrication processes, even with the same materials. Zhang et al. [28] observed the porosity and mechanical properties of 3D scaffolds, which depend on the processing method of the bio-ink materials. The materials were composed of hydroxyapatite (HA) and, according to the processing method, the porous and mechanical properties were measured differently. It was found that the initial materials influenced the fabrication process, by affecting the shrinkage after sintering, which is related to both the porosity and the compressive strength. Indeed, bone scaffolds made with 3D printers have shown low mechanical properties compared with those made with traditional methods. Meanwhile, traditional methods have been developed in a variety of ways, including gas forming, phase separation, and solvent casting [26]. Kim et al. created HA scaffolds using the freeze-gel casting method, which combines freeze casting and gel casting [29]. The HA scaffold had high mechanical properties indicating a higher compressive stress than $35 \mathrm{MPa}$, but unfortunately the porosity was significantly lower. Kim et al. [21] also adopted freeze-gel casting methods for manufacturing biphasic calcium phosphate (BCP) scaffolds. 
They obtained similar results, with very high mechanical strength but a somewhat lower porosity. Therefore, research should continue to try and overcome the difficulties of fabricating bone scaffolds similar to cancellous bone having a porosity of 50 to $90 \%$ or more than $75 \%$ and the compressive strength of $1-12 \mathrm{MPa}[7,30]$.

In this study, artificial bone scaffolds with good porous and mechanical properties similar to cancellous bone were fabricated. The structural changes occurring inside the scaffold during the fabrication process were observed in order to examine the origin of the good mechanical properties of high-porosity scaffolds. A freeze-gel casting method for high compressive strength $[21,29,31]$ was used to prepare highly porous HA scaffolds. The main material was artificial HA, which is similar to the component of cancellous bone, and the microstructure of the scaffolds was controlled by adding different amounts of the porogen poly (methyl methacrylate) (PMMA) [19]. In this process, tert-butyl alcohol (TBA) was selected as the freezing solvent, which created columnar pore channels by removing itself during freeze-drying [32,33]. The fabricated porous HA scaffolds were characterized with regard to their crystalline phase, microstructure, and physical and mechanical properties. Then, the observed structure and tendency of the variation of the properties were analyzed for determining why highly porous scaffolds have higher compressive strength than less porous scaffolds.

\section{Materials and Methods}

\subsection{Scaffold Preparation}

Calcined HA powder (Alfa Aesar, Haverhill, Massachusetts, USA) with an average particle size of 30-40 $\mu \mathrm{m}$ and PMMA powder (Sigma-Aldrich, St. Louis, Missouri, USA) with an average particle size of approximately $160 \mu \mathrm{m}$ were mixed at different volume ratios; HA/PMMA was $100 \mathrm{vol} \% / 0 \mathrm{vol} \%$, $85 / 15,70 / 30,55 / 45,40 / 60$, and 25/75, respectively. Freeze-gel casting slurries were prepared at $25 \mathrm{vol}$ $\%$ solid loading by adding the mixed powders to a premixed TBA (Junsei, Tokyo, Japan) solution containing mono-functional acrylamide (AM, Sigma-Aldrich, St. Louis, Missouri, USA) and di-functional $\mathrm{N}, \mathrm{N}^{\prime}$-methylenebisacrylamide (MBAM, Sigma-Aldrich, St. Louis, Missouri, USA) as reactive organic monomer gelators with TBA/AM/MBAM (wt \%) = 90/9.6/0.4. Then, $1 \mathrm{wt} \%$ citric acid (Sigma-Aldrich, USA) based on the mixed powder content and $0.25 \mathrm{wt} \%$ Dynol604 (Sigma-Aldrich, St. Louis, Missouri, USA) based on the TBA solution were added to the slurries. The prepared TBA-based slurry was stirred at $40^{\circ} \mathrm{C}$ for $24 \mathrm{~h}$ and then stabilized at $40^{\circ} \mathrm{C}$ in a water bath. For the stabilization in the water bath, an aqueous solution of $40 \mathrm{wt} \%$ free-radical initiator, namely, ammonium persulphate (Kanto Chemical, Tokyo, Japan), was slowly dropped into the slurries. Then, the prepared slurries were injected into Teflon cylindrical molds ( $25 \mathrm{~mm}$ in diameter) at the beginning of partial gelation. Subsequently, the molds, whose top and sides were protected with an insulating material, were placed on a plate cooled at a cryogenic temperature, resulting in uniaxial freezing of the TBA from the bottom to the top. The unidirectional TBA solidification provided pore channels throughout the whole cast body for its sublimation. Afterward, the frozen specimens were sublimed and dried for $24 \mathrm{~h}$ in a freeze dryer (SFDSF06, 31Naengyeol, Busan, Korea), causing longitudinal pore channels in a green body. Then, the dried specimens were heated in an electric furnace (Chamber furnace, UAF 15/5, Lenton, Hope Valley, UK) with the temperature set at $1{ }^{\circ} \mathrm{C} / \mathrm{min}$ and maintained at $600{ }^{\circ} \mathrm{C}$ for $1 \mathrm{~h}$ to remove the PMMA and residual organic materials. Next, they were sintered at $1200^{\circ} \mathrm{C}$ for $2 \mathrm{~h}$. The scaffolds were classified as HA0, HA15, HA30, HA45, HA60, and HA75 according to the PMMA addition amount; for example, HA0 had 0 vol \% PMMA. The fabrication of the scaffolds is schematically illustrated in Figure 1.

\subsection{Characterization}

\subsubsection{X-ray Diffraction (XRD)}

An X-ray diffractometer (Ultima 4, Rigaku, Tokyo, Japan, tube anode: $\mathrm{CuK} \alpha ; \lambda: 1.54 \AA$ ) was used to analyze the crystal phase of the HA particles and the HA scaffolds according to the PMMA addition 
amount before and after sintering. The samples were scanned with $2 \theta$ values ranging from 20 to $70^{\circ}$ with a scan speed of $2^{\circ} / \mathrm{min}$.

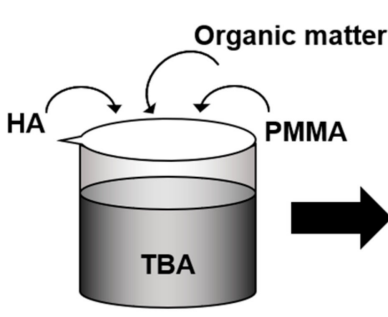

(a) Powder mixing (b) Stirring $\left(40^{\circ} \mathrm{C}, 24 \mathrm{~h}\right)$

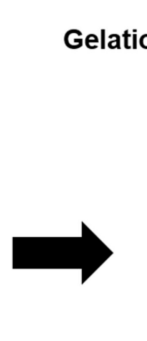

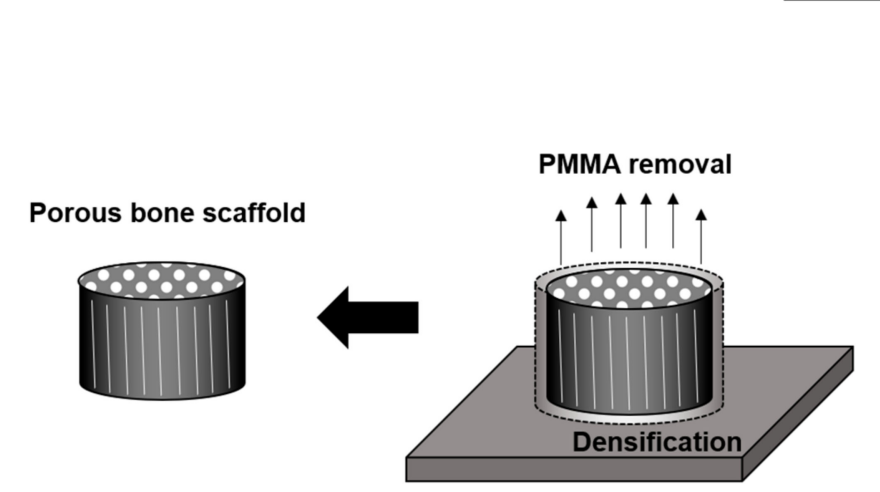

(e) Sintering $\left(1200^{\circ} \mathrm{C}\right)$

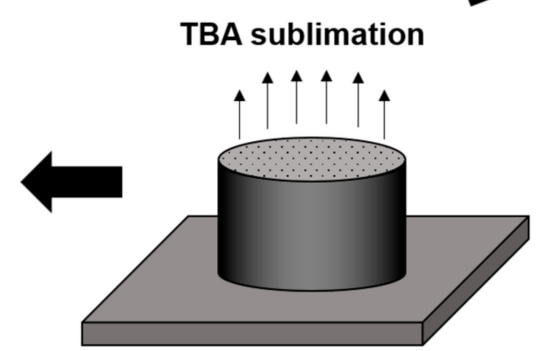

(d) Freeze drying

Figure 1. Freeze-gel casting steps with different PMMA addition amounts to obtain novel porous structures of the bone scaffolds.

\subsubsection{Physical Characterization}

The weight of each specimen $(n=3)$ was measured before and after sintering to confirm the removal of the PMMA and residual organic matter. The bulk density and porosity were measured for four specimens via Archimedes' method using water. The size (diameter and height) of the scaffolds before and after sintering was measured to evaluate the linear shrinkage $(n=4)$.

\subsubsection{Structural Characterization}

Scanning electron microscopy (SEM, SUPRA25, Zeiss, Oberkochen, Germany) was used for microstructure observation. The shape of the pores in the cross-section perpendicular to the casting direction of the porous sintered body and the microstructure of the HA particles in the pore channel walls were observed. The pore size and pore channel wall thickness were calculated via SEM imaging software (SmartSEM, 05.06.05, Zeiss, Oberkochen, Germany). The surface of the specimens was precisely polished with $\mathrm{SiC}$ paper and washed in ethanol using an ultrasonic washing machine (Ultrasonic bath, CPX3800H-E, Branson, Danbury, Connecticut, USA).

The 3D structure of each sintered scaffold was photographed using a Micro-CT (SKYSCAN 1272, Bruker, Konitch, Belgium). A resolution of $21 \mu \mathrm{m}$ was used, with the following acquisition conditions: $90 \mathrm{kV}, 111 \mu \mathrm{A}$, a rotation step of $0.25^{\circ}$, a $0.5 \mathrm{~mm}$ Al filter with a $0.038 \mathrm{~mm} \mathrm{Cu}$ filter, and an exposure time of 1740 ms. The NRecon (1.7.1, Bruker, Konitch, Belgium) software was used to reconstruct the acquired image slices. Approximately 900 slices per sample were generated. The reconstructed images were processed by the CTAn software (1.17, Bruker, Konitch, Belgium). Custom processing was applied to selected regions of interest (ROIs) of the samples, fitting them exactly. Adaptive thresholding was applied according to the localized analysis of density, to minimize the partial volume effect and thickness biasing [34]. The overall porous structure of the specimens, including the pore diameter, size, and distribution, as well as the wall thickness of each pore channel wall were analyzed. 


\subsubsection{Mechanical Characterization}

Each sintered specimen was cut to $20 \mathrm{~mm}$ in diameter and $8 \mathrm{~mm}$ in height using a multi-cutter (ISOMET4000, Buehler, Lake Bluff, IL, USA), and then both sides of the specimen were polished with $1 \mu \mathrm{m}$ diamond paste. The compressive strength and the compressive modulus were measured at a strain rate of $0.5 \mathrm{~mm} / \mathrm{min}[24,29,32,35]$ using a $10.0 \mathrm{kN}$ load cell universal testing machine (UTM, AG-X, Shimadzu, Kyoto, Japan).

\section{Results}

\subsection{Crystalline Phases}

HA powder calcined at $1000^{\circ} \mathrm{C}$ was analyzed using XRD, and an HA phase was observed, which was consistent with the HA of ICSD No. 01-072-1243 (Figure 2a). This indicates that the PMMA and residual organics were completely removed. On the other hand, Figure $2 b$ shows the XRD pattern of the porous scaffolds before and after sintering at $1200^{\circ} \mathrm{C}$. In the case of HA0, which did not contain PMMA, the XRD peak showed a higher strength and narrower width after sintering than before sintering.
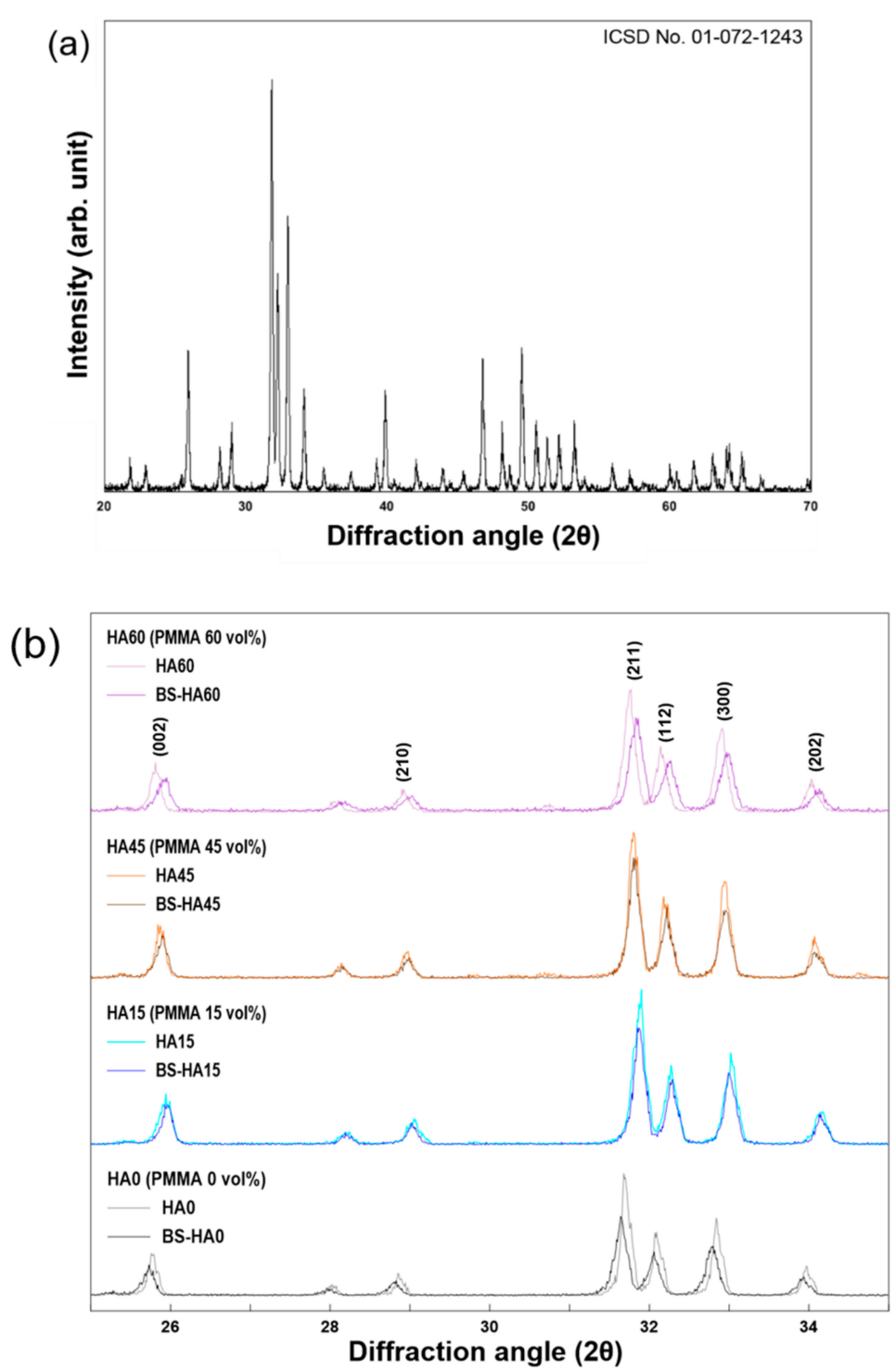

Figure 2. XRD patterns of (a) hydroxyapatite (HA) powder and (b) HA scaffolds before and after sintering ("BS" means "before sintering"). 


\subsection{Physical Properties}

\subsubsection{Weight Loss}

The weight ratio of the scaffolds before and after sintering corresponded to the ratio of the HA weight to the total weight of the material. Therefore, it was expected that the PMMA and residual organics were removed. Table 1 shows experimental results compared with the theoretical weight ratio. Three specimens per type of the scaffolds (S1, S2, and S3) were measured and calculated. By confirming $p>0.05$ using the paired $t$-test, it could be seen that there was no difference between the theoretical results and the experimental results. The porous scaffolds sintered completely were only composed of HA powder. It is known that PMMA is used as a porogen by being vaporized and removed from the scaffolds $[19,34]$. In this study, the PMMA was completely removed and produced the pores all over the inside of the artificial scaffold.

Table 1. Comparison of the weight ratio between theoretical and experimental results before and after sintering for verification of the removal of PMMA and residual organics.

\begin{tabular}{|c|c|c|c|c|c|c|c|}
\hline \multirow[b]{3}{*}{ PMMA Addition (vol \%) } & \multirow[b]{3}{*}{ HA (g) } & \multicolumn{2}{|c|}{ Theoretical Result } & \multirow{2}{*}{\multicolumn{4}{|c|}{$\begin{array}{c}\text { Experimental Result (Weight Ratio) } \\
\text { Ratio }^{\mathbf{b}} \text { (After Sintering/Before Sintering) }\end{array}$}} \\
\hline & & \multirow[b]{2}{*}{ Total (g) } & \multirow[b]{2}{*}{ Ratio $^{\text {a }}$ (HA/Total) } & & & & \\
\hline & & & & S1 & S2 & S3 & $\begin{array}{l}\text { Mean in Difference } \\
\text { (Ratio }^{\text {a }} \text {-Ratio } \\
\text { b) }\end{array}$ \\
\hline 0 & 31.40 & 34.76 & 0.90 & 0.92 & 0.90 & 0.91 & $0.01 \pm 0.01 *$ \\
\hline 15 & 26.69 & 31.81 & 0.84 & 0.84 & 0.84 & 0.84 & $0 \pm 0$ * \\
\hline 30 & 21.98 & 28.85 & 0.76 & 0.76 & 0.76 & 0.76 & $0 \pm 0$ * \\
\hline 45 & 17.27 & 25.9 & 0.67 & 0.69 & 0.66 & 0.66 & $0.003 \pm 0.01 *$ \\
\hline 60 & 12.56 & 22.94 & 0.55 & 0.54 & 0.54 & 0.54 & $-0.01 \pm 0 *$ \\
\hline 75 & 9.42 & 21.56 & 0.44 & 0.43 & 0.43 & 0.43 & $-0.01 \pm 0$ * \\
\hline
\end{tabular}

\subsubsection{Porosity and Linear Shrinkage}

Table 2 shows the porosity and linear shrinkage of both the height and cross-sectional diameter of the HA scaffolds according to the amount of PMMA added. The porosity of the 6 scaffold types was variously shown within the wide porosity range of cancellous bone. From HA0 to HA45, porosity was less than $75 \%$, and for HA60 and HA75, it was over $75 \%$. Considering that the porosity of the longitude direction for cancellous bone was observed to be more than $75 \%$, it was shown that only scaffolds with high porosity could be applied to areas placed in a particular direction, and that HA60 and HA75 could be applied. The results of the linear shrinkage are shown schematically in Figure 3. A larger amount of PMMA yielded a higher porosity and a greater linear shrinkage. The shrinkage of the diameter of the HA was approximately double that of the height. In contrast, for HA75, the shrinkage of the diameter was approximately $7 \%$ lower than that of the height. Compared with HA0, the shrinkage of the diameter for HA75 was $20 \%$ greater, and the shrinkage of the height was $5 \%$ greater.

Table 2. Linear shrinkage for each diameter and height of the HA scaffolds with respect to the PMMA addition amount $(n=4)$.

\begin{tabular}{cccc}
\hline \multirow{2}{*}{ PMMA Addition (vol \%) } & Porosity (\%) & \multicolumn{2}{c}{ Linear Shrinkage (\%) } \\
\cline { 3 - 4 } & & Height & Diameter \\
\hline 0 & $53.2 \pm 3.9^{\mathrm{d}}$ & $7.1 \pm 1.3^{* *}$ & $14.6 \pm 2.1^{*}$ \\
15 & $54.0 \pm 1.2^{\mathrm{d}}$ & $8.8 \pm 4.5^{* *}$ & $15.7 \pm 2.2^{*}$ \\
30 & $62.5 \pm 0.8^{\mathrm{c}}$ & $10.3 \pm 4.9^{* *}$ & $15.3 \pm 2.8^{*}$ \\
45 & $72.1 \pm 1.0^{\mathrm{b}}$ & $17.4 \pm 9.2^{* *}$ & $20.3 \pm 0.5^{*}$ \\
60 & $81.8 \pm 0.7^{\mathrm{a}}$ & $22.7 \pm 8.5^{* *}$ & $19.3 \pm 3.7^{*}$ \\
75 & $88.1 \pm 1.1^{\mathrm{a}}$ & $27.5 \pm 7.4^{* *}$ & $20.4 \pm 3.7^{*}$ \\
Cancellous bone & $50-90 \%\left(>75^{*}\right)[30,36]$ & & \\
\hline
\end{tabular}

a,b,c,d Values with different superscripts in the same parameter are significantly different at $p<0.001$. ${ }^{* *}$ Significant difference between groups (height shrinkage) at $p<0.01$. Significant difference between groups (diameter shrinkage) at $p>0.05$. 


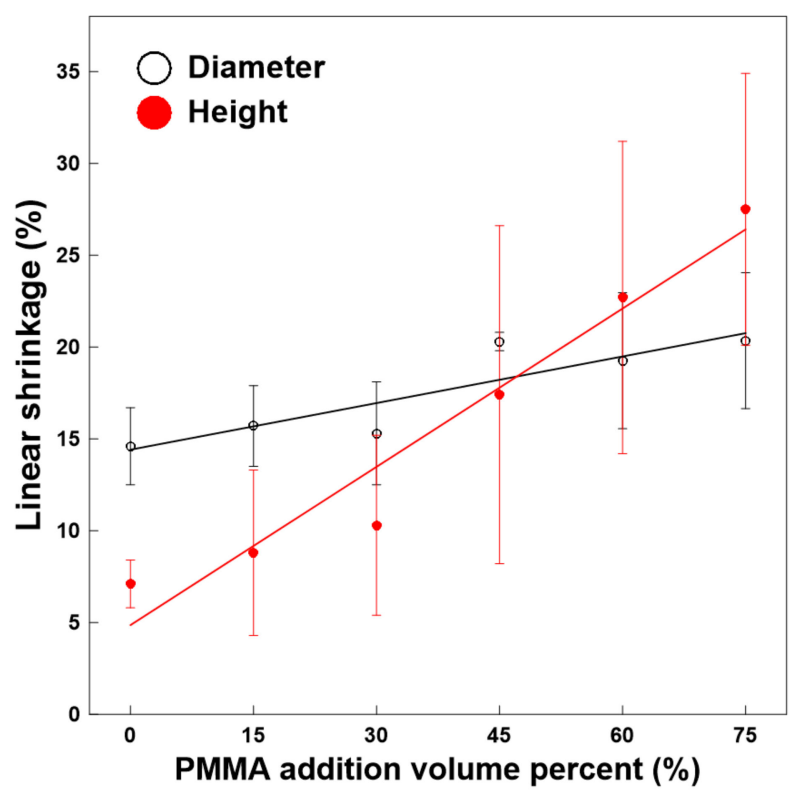

Figure 3. Linear shrinkage for each diameter and height of the scaffolds; the paired $t$-test for difference between height shrinkage and diameter was carried out and $p<0.001$.

\subsubsection{Density and Density Growth Rate}

As shown in Table 3, the apparent density decreased with the decrease of the mass, as the amount of PMMA removed during sintering increased from HA0 to HA75. The results of the bone mineral density (BMD) from the Micro-CT obtained using 0.25 and $0.75 \mathrm{~g} / \mathrm{cm}^{3}$ of the BMD standard phantom corresponded to the tendency of the apparent density. BMD is defined as the volumetric density of calcium HA (CaHA) in a biological tissue (in $\mathrm{g} / \mathrm{cm} 3$ ). It is calibrated using phantoms with a known density of CaHA [37]. The BMD after the sintering process was higher than that before the sintering process. As the amount of PMMA added increased, the BMD of the scaffold both before and after sintering decreased. However, as the amount of PMMA increased, it was observed that the difference in BMDs before and after sintering increased. Specifically, after sintering, HA75 became approximately 2.5 times denser than before sintering, whereas HA0 became approximately doubly denser (Figure 4).

Table 3. Apparent density and bulk specific gravity of the HA scaffolds with respect to the PMMA addition amount.

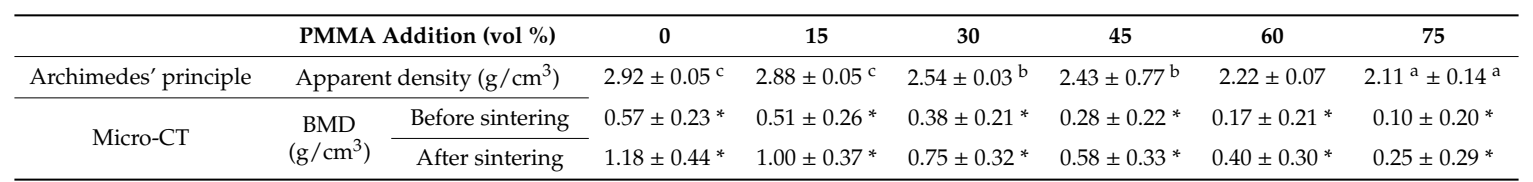

$\mathrm{a}, \mathrm{b}, \mathrm{c}$ Values with different superscripts in the same parameter are significantly different at $p<0.001 .{ }^{*}$ Significant difference between BMD before sintering and after sintering at $p<0.001$. 


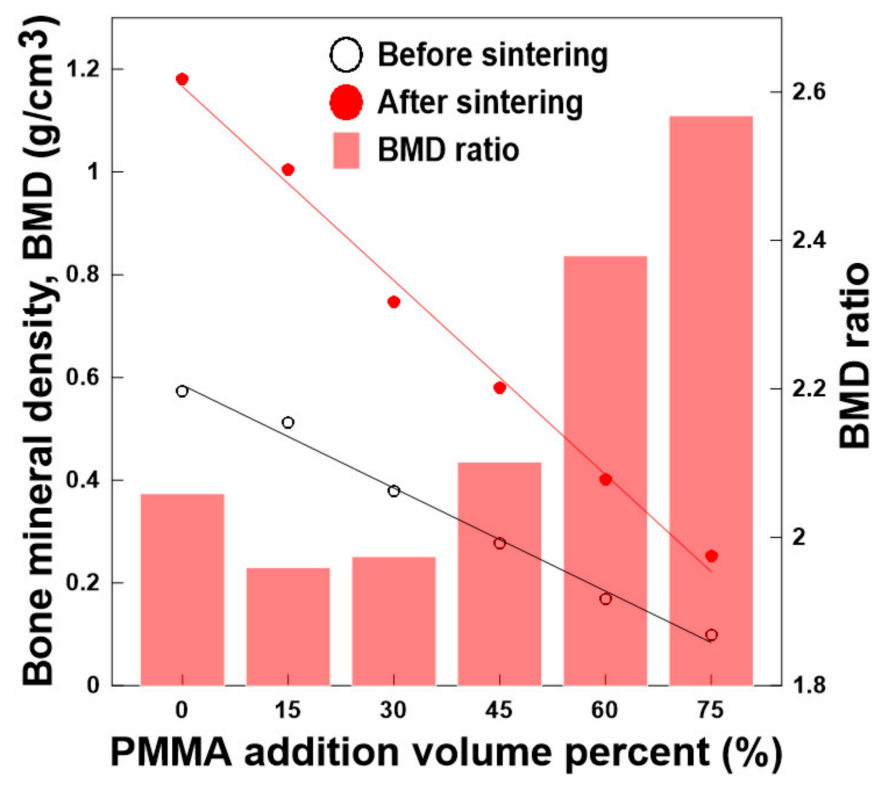

Figure 4. Bone mineral density (BMD) before and after sintering and the BMD ratio (the results after sintering/the results before sintering) with respect to the PMMA addition amount; the paired $t$-test for difference between BMD before sintering and BMD after sintering was carried out and $p<0.001$.

\subsection{Structure of HA Scaffolds}

\subsubsection{D Structure and Porous Properties}

Figure 5 shows the 3D structure of the artificial bone scaffolds. There were more pores after sintering than before sintering. It is considered that PMMA vaporization during sintering at approximately $200^{\circ} \mathrm{C}$ played a major role in the pore formation. A larger amount of PMMA added led to a larger number of pores being observed. This indicates that the amount of PMMA affected the pore formation. Additionally, the porosity and water absorption measured using Archimedes' principle of scaffolds increased with the amount of PMMA (Table 2).

The average pore size and pore-size distribution of the bone scaffolds are shown in Figure 6. The results indicate that the mean and maximum pore sizes increased with the amount of PMMA. The average particle size of PMMA was $158.3 \mu \mathrm{m}$, and the mode was $168.9 \mu \mathrm{m}$. However, the size of the pores observed inside the scaffolds was $>500 \mu \mathrm{m}$. The mean pore size of HA0 observed after the sublimation of TBA in the freeze-drying step (i.e., before sintering) was $89.34 \mu \mathrm{m}$, and most of the pores were distributed in the range of 65-108 $\mu \mathrm{m}$. However, as the amount of PMMA increased, the average pore size increased, and the pore-size distribution became wider (Figure 6b). The pore-size distribution after sintering was wider than that before sintering, as shown in Figure 6c. This is presumably because the cylindrical pore channels having a diameter of approximately $20 \mu \mathrm{m}$ (Figure 7a) formed when the TBA was sublimed and dried, serving as a passage through which the PMMA having an average size of $158 \mu \mathrm{m}$ was vaporized and escaped. 
(a)

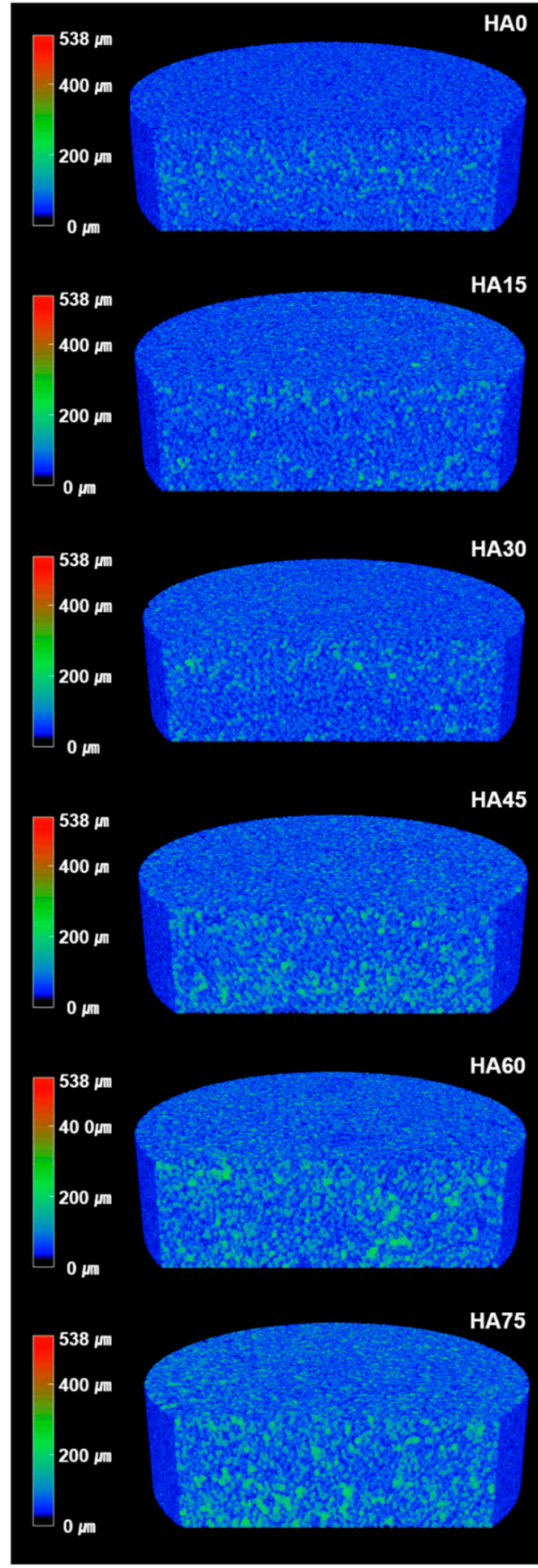

(b)

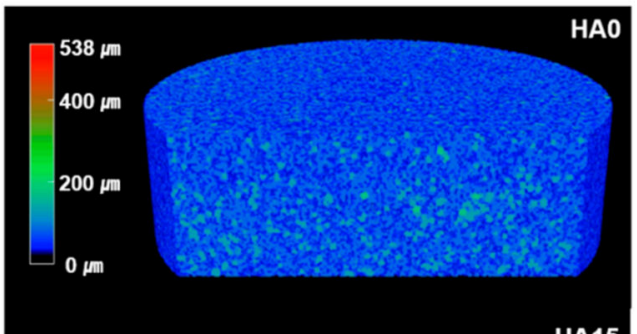

538 н

$400 \mu \mathrm{m}$

$200 \mu \mathrm{mII}$

$\square_{0}$

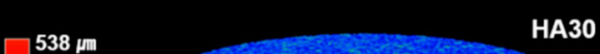

$400 \mu \mathrm{m}$

$200 \mu \mathrm{m}$

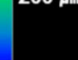

$\mathbf{0} \boldsymbol{\mu m}$

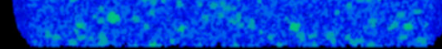

538

$538 \mu \mathrm{m}$
$400 \mu \mathrm{m}$

200 pm

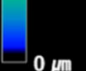

$0 \boldsymbol{\mu n}$
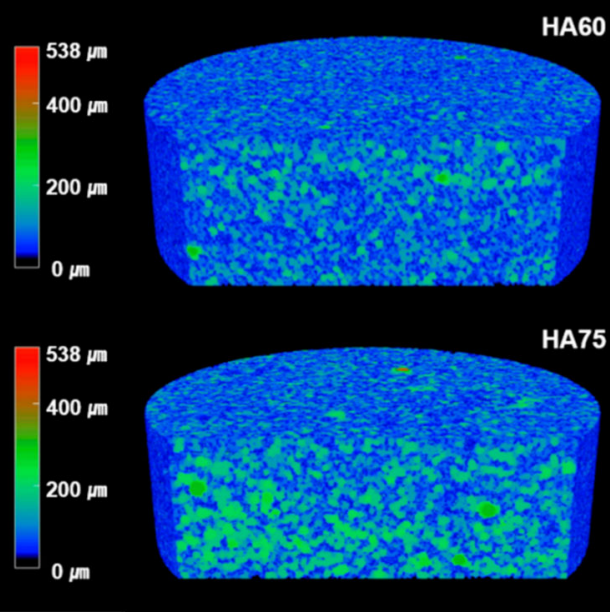

Figure 5. Microcomputed tomography morphologies of the 3D structure and the internal constitution of HA scaffolds, (a) before sintering and (b) after sintering. 
(a)

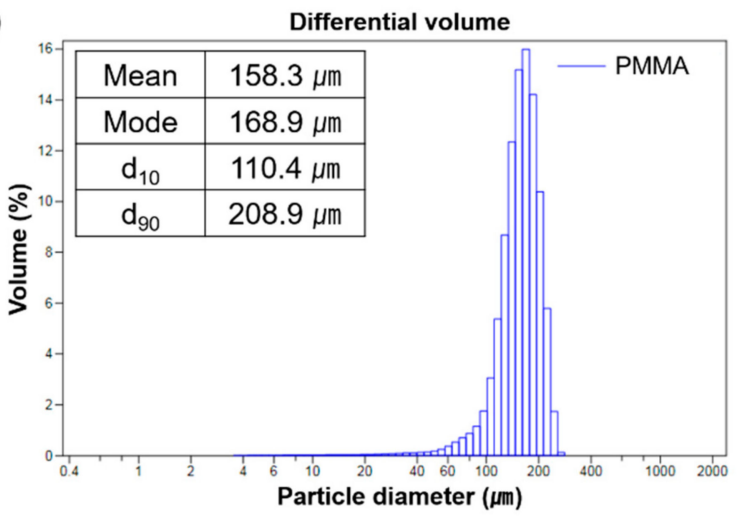

(b)
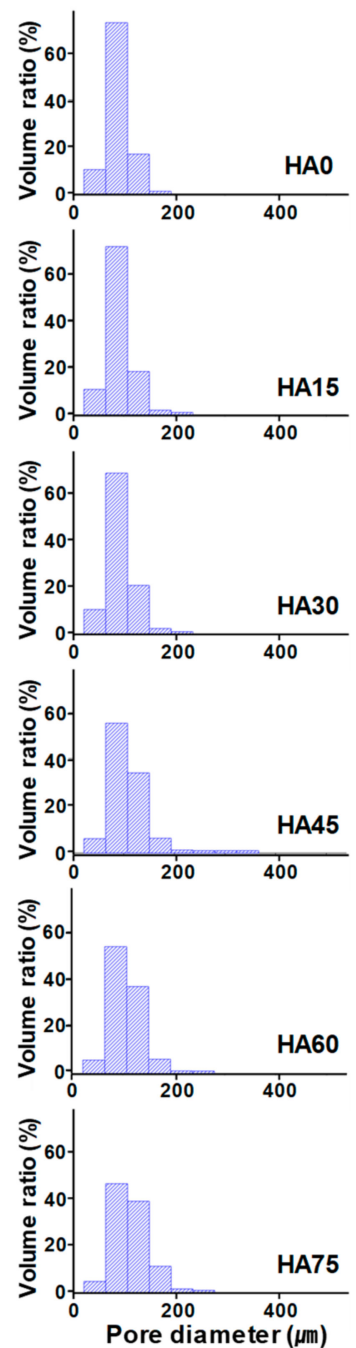

(c)
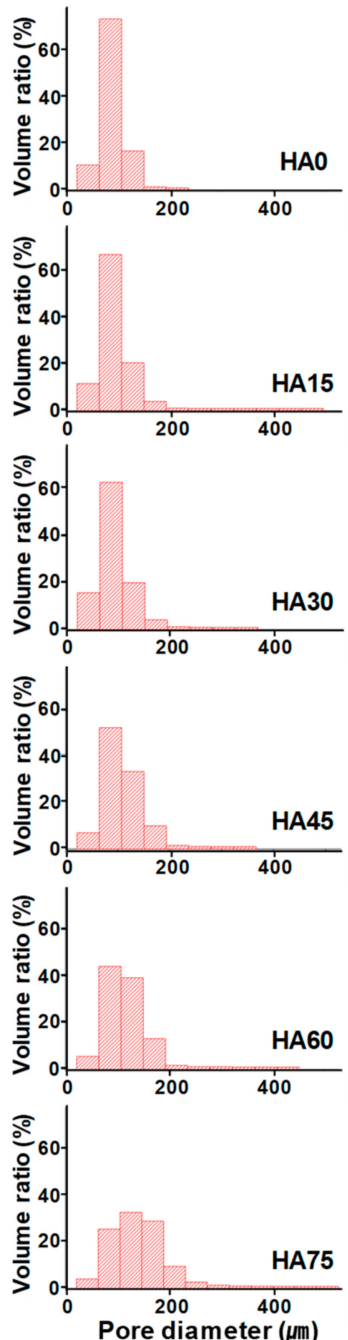

Figure 6. (a) Particle size distribution of PMMA powder; pore size distribution of HA scaffolds with respect to the PMMA addition amount, (b) before sintering and (c) after sintering.

\subsubsection{Surface and Cross-Section}

As shown in Figure 7, the HA scaffolds were observed via SEM parallel and perpendicular to the freezing direction of the TBA solvent. The porogen (PMMA) and residual organic materials were removed completely during the sintering process, and then pores of various sizes were formed. With the increase of the amount of PMMA (i.e., from HA0 to HA75) a larger number of pores and macropores was observed on the surface. 

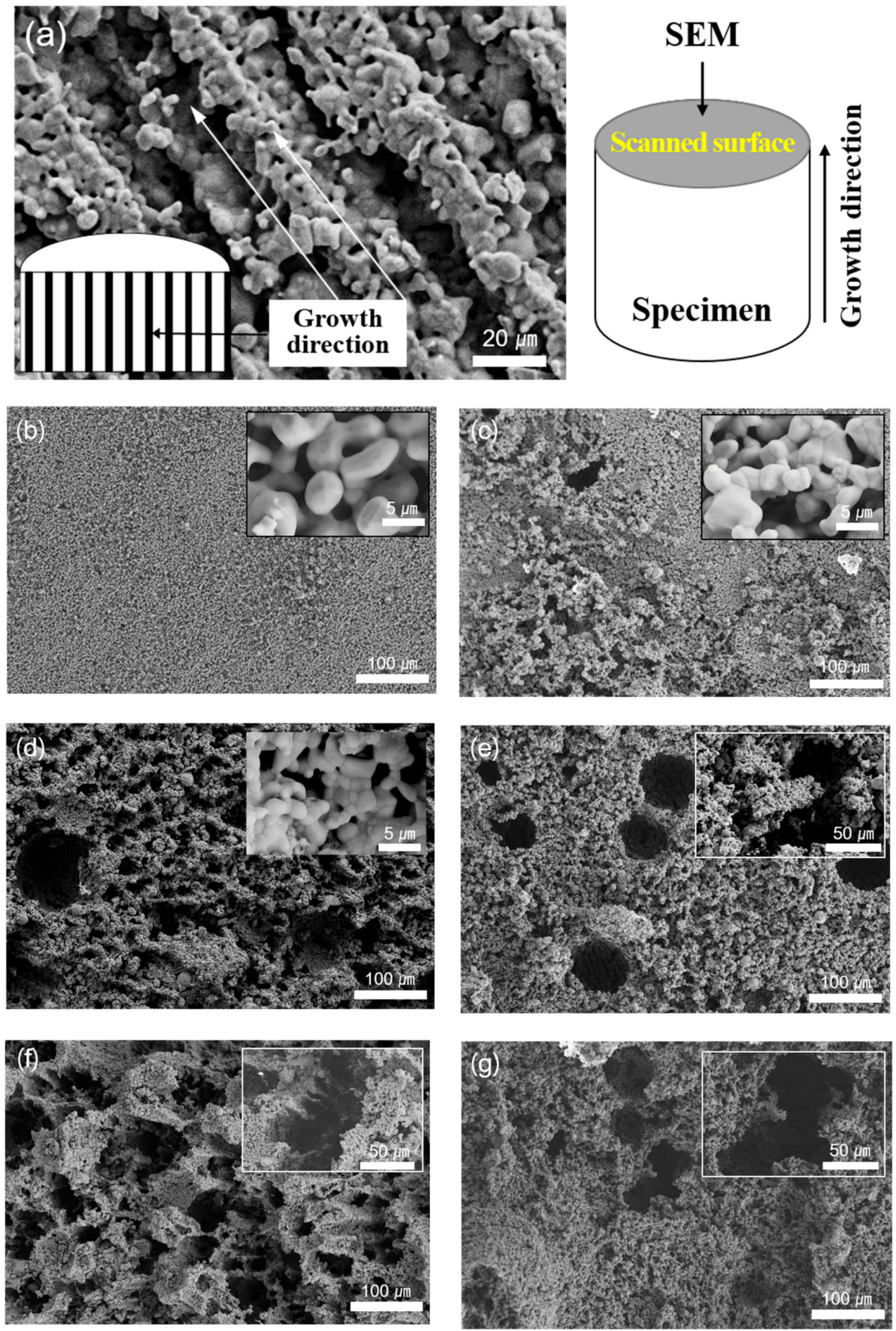

Figure 7. (a) SEM images of cross-section parallel to the macroscopic tert-butyl alcohol (TBA) freezing growth direction of $\mathrm{HA} 0$; and the images of surface perpendicular to the macroscopic TBA freezing growth direction: (b) HA0, (c) HA15, (d) HA30, (e) HA45, (f) HA60, and (g) HA75. 


\subsubsection{Wall Thickness}

It has been reported that a thicker wall between the pores of the artificial scaffolds yields better mechanical properties, including the compressive strength [38,39]. Additionally, the wall thickness and porosity were known to be inversely related [40]. However, in this study, there is no significant difference in the wall thickness among HA0 to HA75 at the before sintering state (Figure 8a). This phenomenon was also observed after the sintering process (Figure $8 \mathrm{~b}$ ). The difference in the wall thickness between the before sintering and after sintering states tended to increase as the amount of PMMA addition increased. As shown in Table 4, the average wall thickness of HA0 exhibited no significant difference between before and after sintering, whereas at HA75, the average wall thickness increased about $5 \mu \mathrm{m}$ after sintering. Moreover, as the amount of PMMA increased, the range of the wall thickness became broader.

(a)
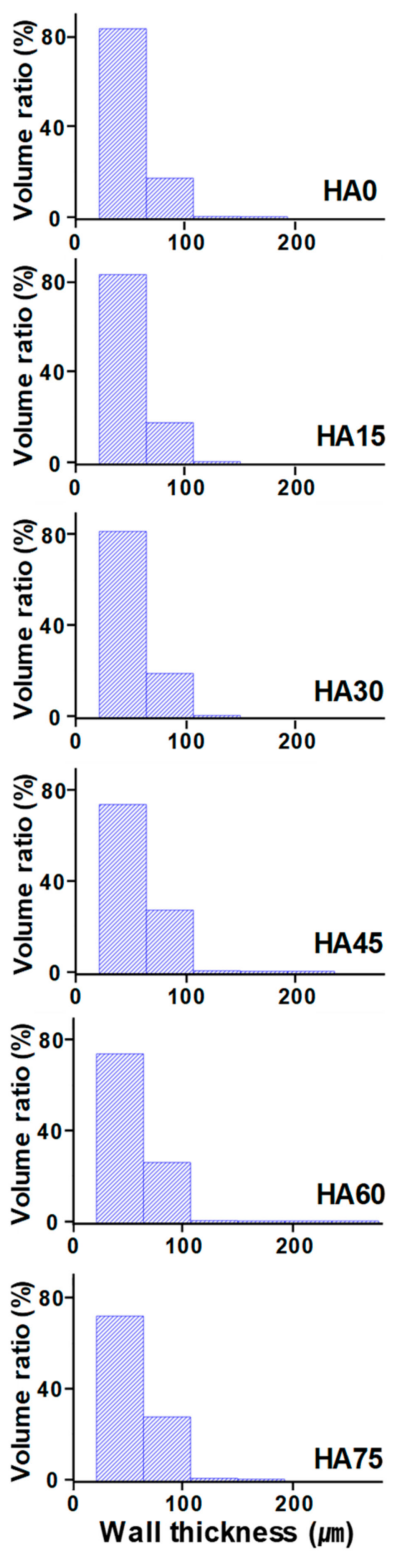

(b)
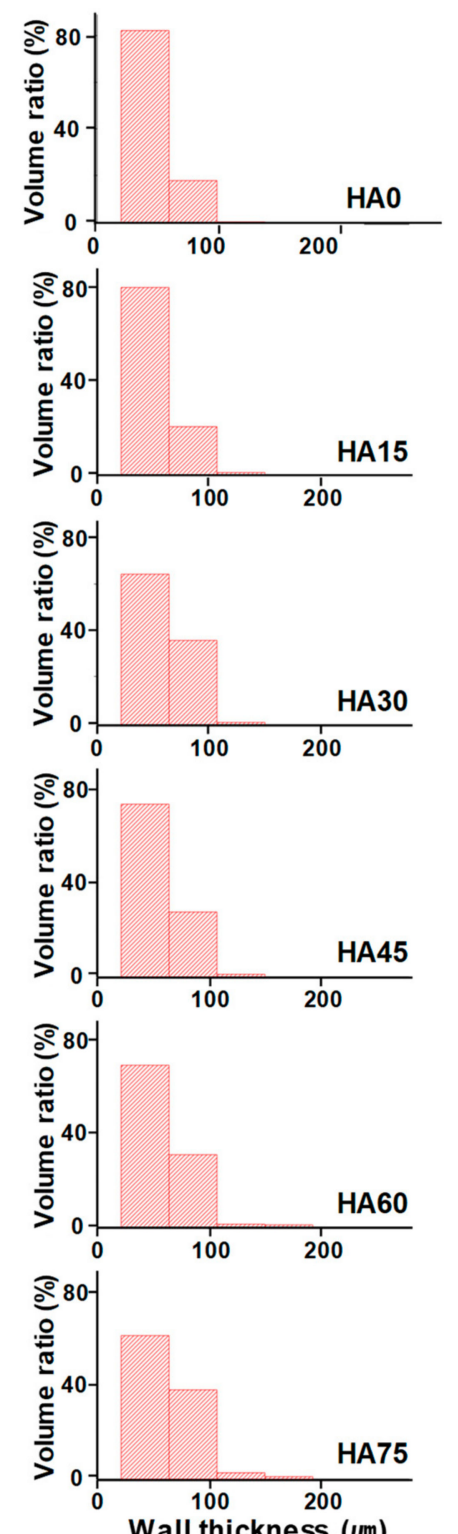

Figure 8. Wall thickness distribution of the scaffolds with respect to the PMMA addition amount, before sintering and after sintering. 
Table 4. Mean wall thickness of the scaffolds with respect to the PMMA addition amount, before sintering and after sintering.

\begin{tabular}{cccc}
\hline & \multicolumn{2}{c}{ Mean Wall Thickness $(\mu \mathrm{m})$} & $\begin{array}{c}\text { Difference in Means } \\
\left|\boldsymbol{m}^{\prime}-\boldsymbol{m}\right|(\boldsymbol{\mu})\end{array}$ \\
\hline PMMA Addition (vol \%) & Before Sintering $(\mathbf{m} \pm \boldsymbol{\sigma})$ & After Sintering $\left(\mathbf{m}^{\prime} \pm \boldsymbol{\sigma}^{\prime}\right)$ & $0.34^{* *}$ \\
15 & $50.42 \pm 16.22^{*}$ & $50.76 \pm 16.51^{*}$ & $0.96^{* *}$ \\
30 & $50.69 \pm 16.36^{*}$ & $51.65 \pm 17.20^{*}$ & $7.41^{* *}$ \\
45 & $51.13 \pm 16.81^{*}$ & $58.54 \pm 20.76^{*}$ & $0.2^{* *}$ \\
60 & $54.82 \pm 19.42^{*}$ & $54.62 \pm 19.21^{*}$ & $2.14^{* *}$ \\
75 & $54.39 \pm 19.44^{*}$ & $56.53 \pm 20.33^{*}$ & $5.6^{* *}$ \\
\hline
\end{tabular}

${ }^{*}$ Significant difference between groups (before and after sintering, respectively) at $p>0.05 .{ }^{* *}$ indicates the statistical significance with $p<0.01$ using the paired $t$-test for the difference in means.

\subsection{Mechanical Properties}

HA0 was a control group that did not contain PMMA, and it was observed that HA15 had the average values of the porosity and the apparent density similar to those of HA0. Although HA60 and HA75 were two types of scaffold with a porosity of more than 75\%, HA60 was expected to exhibit relatively high mechanical properties. Thus, HA0 and HA60 were adopted to evaluate the mechanical properties among the 6 scaffold types. In addition, HA30 had the medium values between HA0 and HA60 for the properties such as porosity and density. Consequently, the three scaffold types HA0, HA30, and HA60 were selected. The compressive strength of HA0, HA30, and HA60 was $6.18,1.73$, and $3.23 \mathrm{MPa}$, respectively, and the porosity was $52.7 \%, 62.9 \%$, and $81.9 \%$, respectively. Compared with HA30, the scaffold HA60, which had approximately $30 \%$ higher porosity, exhibited mechanical properties approximately two times better. This result contradicts previous studies indicating that there is a linear inverse relationship between porosity and compressive strength. All three types of scaffolds satisfied the compressive-strength range of cancellous bone. On the other hand, HA60 had the highest compressive elastic modulus (Table 5). HA0 and HA60 were consistent with the modulus range of cancellous bone, and HA30 had a smaller modulus than real bone. Figure 9 shows the stress-strain curves obtained in the compression test of the three types of scaffolds.

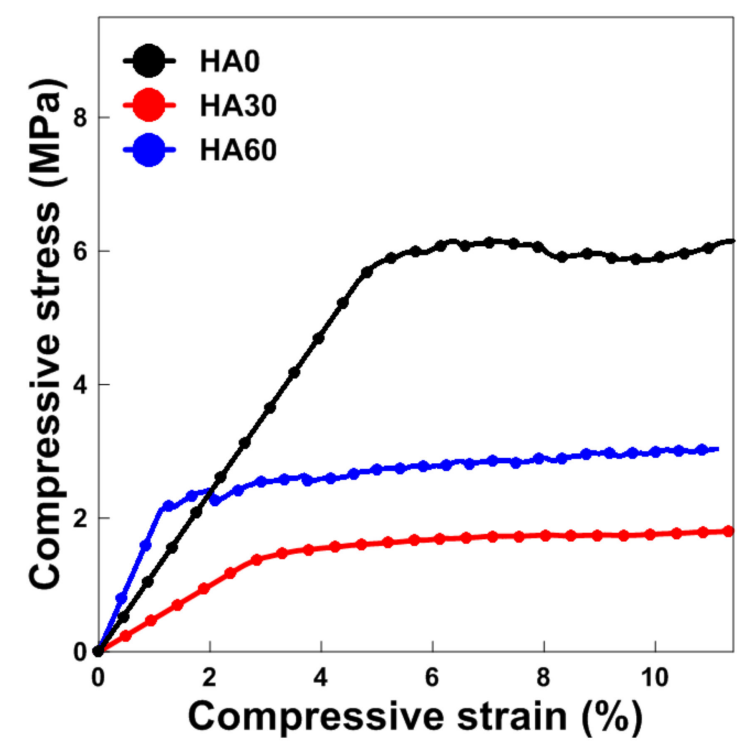

Figure 9. Compressive stress-strain curve for the HA scaffolds. 
Table 5. Mechanical properties of the HA scaffolds and human cancellous bone $(n=5)$.

\begin{tabular}{ccc}
\hline & Compressive Elastic Modulus (GPa) & Compressive Strength (MPa) \\
\hline HA0 & $0.13 \pm 0.04^{\mathrm{a}, \mathrm{b}}$ & $6.18 \pm 0.28^{\mathrm{a}}$ \\
HA30 & $0.05 \pm 0.02^{\mathrm{b}}$ & $1.73 \pm 0.22^{\mathrm{b}}$ \\
HA60 & $0.19 \pm 0.08^{\mathrm{a}}$ & $3.23 \pm 0.75^{\mathrm{b}}$ \\
Cancellous bone & $0.12-1.1[7]$ & $1-12[7,30]$ \\
\hline a,b Values with different superscripts in the same parameter are significantly different $(p<0.01)$.
\end{tabular}

\section{Discussion}

Research for developing artificial bone scaffolds as implants into the human body has been actively conducted, with a focus on the porous and mechanical properties of the implants. Therefore, this study focused on the porous and compressive properties of artificial bone scaffolds. In numerous previous studies, an inverse correlation between the porosity and the compressive strength of scaffolds was reported [20-24,34]. However, the present study indicated that the relationship between the porosity and the compressive strength is not necessarily inversely proportional. The porosity and compressive strength of HA30 were $62.9 \%$ and $1.73 \mathrm{MPa}$, respectively, while those of HA60 were $81.9 \%$ and $3.23 \mathrm{MPa}$, respectively. The compressive elastic modulus increased in the order of HA60, HA0, and HA30. The porosity of HA60 was $40 \%$ higher than that of HA30, and the compressive strength was approximately twice as high. Furthermore, the compressive strength and compressive elastic modulus of HA60 were similar to those of cancellous bone.

On the basis of these findings, the rate of change in the linear shrinkage after sintering according to the amount of PMMA added can be examined. In the present study, the TBA was sublimed and dried during freeze-drying; thus, the pore channel walls, which can be observed in Figure 7a, were created in a direction perpendicular to the cylindrical scaffolds. Therefore, in the structure of the scaffolds, the shrinkage of the diameter shown in Figure $7 \mathrm{~b}-\mathrm{g}$ can explain the shrinkage of the entrance of the pore channels and the shrinkage of the HA wall. In contrast, the height shrinkage explains the shrinkage of the length of the pore channel observed in Figure 7a. The tendency of the height shrinkage to be greater than the diameter shrinkage indicates that the length of the pore channels decreased more than the pore size of the pore channels. This can be attributed to the channel wall becoming harder owing to the densification. In previous studies, it was concluded that the linear shrinkage and density of porous artificial bone scaffolds are proportional to the mechanical properties and inversely proportional to the porosity. This is consistent with the fact that high shrinkage improved the mechanical properties in the present study. As shown in Figure 3 and Table 2, HA0, HA15, and HA30 had greater shrinkage in diameter than in height, and both shrinkages increased by approximately $1-3 \%$ from HA0 to HA30. However, for HA45, the height shrinkage exceeded the diameter shrinkage. HA60 exhibited height shrinkage of $22.7 \%$ and diameter shrinkage of $19.3 \%$, and the values for HA30 were $10.3 \%$ and $15.7 \%$, respectively. The difference in the height shrinkage was approximately $12 \%$, and that of the diameter shrinkage was approximately $4 \%$. The pore size was not significantly changed by the removal of PMMA during sintering; rather, the length of the pore channels was reduced owing to the densification of the walls made of HA. Because the height shrinkage ratio of HA60 was approximately $12 \%$ larger than that of HA30, the compressive strength was twice as high, although the porosity was approximately $30 \%$ lower.

The rate of increase for the density also resulted in the feasibility of the proportional relationship between the porosity and the compressive strength. The apparent density of the scaffolds increased with the amount of HA. From HA0 to HA75, the apparent density decreased from 2.98 to $2.00 \mathrm{~g} / \mathrm{cm}^{3}$. The BMD both before and after sintering decreased with the addition of PMMA. After sintering, the BMD increased by a factor of 2.6 for HA75, whereas it increased by a factor of 2 for HA0. Although the apparent density and BMD of the sintered HA60 were 2.17 and $0.40 \mathrm{~g} / \mathrm{cm}^{3}$, respectively, which are considerably lower than those of HA30 $\left(2.56\right.$ and $\left.0.75 \mathrm{~g} / \mathrm{cm}^{3}\right)$, the rate of the increase of the BMD was higher for HA60 than for HA30. This result supports the unprecedented phenomenon 
that HA60 had higher compressive strength than HA30. Furthermore, the tendencies of the rate of increase for the density and the linear shrinkage were similar; thus, it was expected that the walls between the pore channels rigidly supported the internal structure of the scaffolds. Tseng et al. suggested that the distance between the pores (i.e., the wall thickness of the pore channel) is one of the variables for calculating the porosity [38]. In other studies, a thicker scaffold wall led to better mechanical properties [40-42]. However, in the present study, the wall thickness and compressive strength were inversely proportional, and wall thickness and porosity tended to be proportional. This shows that it is important to identify the complex mechanism depending on the phenomenon occurring in the manufacturing process, rather than simply comparing the results after the production of the scaffolds. It is necessary to identify the correlation between the changes during the process (e.g., the rate of linear shrinkage, the rate of density increase, and the physical and mechanical characteristics of the scaffolds) and to apply it for manufacturing an optimal artificial bone scaffold to be implanted into the human body.

\section{Conclusions}

The porous and mechanical properties of porous artificial bone scaffolds fabricated via freeze-gel casting methods with a TBA solvent and HA and PMMA powder were evaluated. The porosity and compressive properties of the fabricated scaffolds corresponded to those of cancellous bone. The porosity and compressive strength were proportional, in contrast to the results of previous studies. To explain this peculiar phenomenon, the parameters that can improve the porous structure and the mechanical properties during the manufacturing process were analyzed. Several rates of change in the sintering process were calculated, such as the linear shrinkage rate and the density increase rate. It was confirmed that the values could explain the proportionality of the porosity and compressive strength. Therefore, it is important not only to measure the characteristic value of the manufactured scaffolds but also to clearly show the relationship between the characteristic values by tracking the change in the values in the manufacturing process, as this relationship can be used to predict the physical and mechanical properties of artificial bone scaffolds after they are implanted into a living body. In the present study, the porosity, compressive elastic modulus, and compressive strength of HA60 were similar to those of cancellous bone. In the next study, the biocompatibility of the support and the change in its mechanical properties after implantation will be observed. Additionally, the development of artificial bone scaffolds will be improved.

Author Contributions: Conceptualization, T.-R.K.; methodology, M.-S.K. and S.-Y.Y.; software, T.-R.K.; validation, M.-S.K., and C.-S.L.; formal analysis, T.-R.K. and S.-Y.Y.; investigation, T.S.G. and Y.H.K.; resources, S.-Y.Y. and C.-S.L.; data curation, T.-R.K., J.S.L. writing-original draft preparation, T.-R.K. and C.-S.L.; writing-review and editing, S.-Y.Y. and C-S.L.

Funding: This work was supported by the National Research Foundation of Korea (NRF) grant funded by Ministry of Science and ICT (MSIT) NRF-2018R1C1B6008922.

Conflicts of Interest: The authors declare no conflict of interest. The funders had no role in the study design, data collection and analyses, writing of the manuscript, or in the decision to publish the results.

\section{References}

1. Shahbazi, S.; Zamanian, A.; Pazouki, M.; Jafari, Y.; Zamanyan, A. Introducing an attractive method for total biomimetic creation of a synthetic biodegradable bioactive bone scaffold based on statistical experimental design. Mater. Sci. Eng. C 2018, 86, 109-120. [CrossRef] [PubMed]

2. Tamburaci, S.; Tihminlioglu, F. Biosilica incorporated 3D porous scaffolds for bone tissue engineering applications. Mater. Sci. Eng. C 2018, 91, 274-291. [CrossRef]

3. Yin, H.-M.; Huang, Y.-F.; Ren, Y.; Wang, P.; Zhao, B.; Li, J.-H.; Xu, J.-Z.; Li, Z.-M. Toward biomimetic porous poly ( $\varepsilon$-caprolactone) scaffolds: Structural evolution and morphological control during solid phase extrusion. Compos. Sci. Technol. 2018, 156, 192-202. [CrossRef] 
4. Dhollander, A.A.; Liekens, K.; Almqvist, K.F.; Verdonk, R.; Lambrecht, S.; Elewaut, D.; Verbruggen, G.; Verdonk, P.C. A Pilot Study of the Use of an Osteochondral Scaffold Plug for Cartilage Repair in the Knee and How to Deal with Early Clinical Failures. Arthrosc. J. Arthrosc. Relat. Surg. 2012, 28, 225-233. [CrossRef] [PubMed]

5. Shishkovsky, I.; Volchkov, S. Influence of the laser assisted fabricated 3D porous scaffolds from bioceramoplasts of micron and nano sizes on culture of MMSC. Fundam. Laser Assist. Micro-Nanotechnol. 2013, 9065, 906515.

6. Yamashita, A.; Liu, S.; Woltjen, K.; Thomas, B.; Meng, G.; Hotta, A.; Takahashi, K.; Ellis, J.; Yamanaka, S.; Rancourt, D.E. Cartilage tissue engineering identifies abnormal human induced pluripotent stem cells. Sci. Rep. 2013, 3, 1978. [CrossRef] [PubMed]

7. Gerhardt, L.-C.; Boccaccini, A.R. Bioactive Glass and Glass-Ceramic Scaffolds for Bone Tissue Engineering. Materials 2010, 3, 3867-3910. [CrossRef] [PubMed]

8. Chen, Y.; Kawazoe, N.; Chen, G. Preparation of dexamethasone-loaded biphasic calcium phosphate nanoparticles/collagen porous composite scaffolds for bone tissue engineering. Acta Biomater. 2017, 67, 341-353. [CrossRef] [PubMed]

9. Chang, B.-S.; Lee, C.-K.; Hong, K.-S.; Youn, H.-J.; Ryu, H.-S.; Chung, S.-S.; Park, K.-W. Osteoconduction at porous hydroxyapatite with various pore configurations. Biomaterials 2000, 21, 1291-1298. [CrossRef]

10. Pei, P.; Wei, D.; Zhu, M.; Du, X.; Zhu, Y. The effect of calcium sulfate incorporation on physiochemical and biological properties of 3D-printed mesoporous calcium silicate cement scaffolds. Microporous Mesoporous Mater. 2017, 241, 11-20. [CrossRef]

11. Al-Tamimi, A.A.; Peach, C.; Fernandes, P.R.; Cseke, A.; Bartolo, P.J. Topology Optimization to Reduce the Stress Shielding Effect for Orthopedic Applications. Procedia CIRP 2017, 65, 202-206. [CrossRef]

12. Pobloth, A.-M.; Checa, S.; Razi, H.; Petersen, A.; Weaver, J.C.; Schmidt-Bleek, K.; Windolf, M.; Tatai, A. Á.; Roth, C.P.; Schaser, K.-D.; et al. Mechanobiologically optimized 3D titanium-mesh scaffolds enhance bone regeneration in critical segmental defects in sheep. Sci. Transl. Med. 2018, 10, 423. [CrossRef] [PubMed]

13. Soon, Y.-M.; Shin, K.-H.; Koh, Y.-H.; Lee, J.-H.; Choi, W.-Y.; Kim, H.-E. Fabrication and compressive strength of porous hydroxyapatite scaffolds with a functionally graded core/shell structure. J. Eur. Ceram. Soc. 2011, 31, 13-18. [CrossRef]

14. Song, P.; Zhou, C.; Fan, H.; Zhang, B.; Pei, X.; Fan, Y.; Jiang, Q.; Bao, R.; Yang, Q.; Dong, Z.; et al. Novel 3D porous biocomposite scaffolds fabricated by fused deposition modeling and gas foaming combined technology. Compos. Part B Eng. 2018, 152, 151-159. [CrossRef]

15. Hammel, E.; Ighodaro, O.-R.; Okoli, O. Processing and properties of advanced porous ceramics: An application based review. Ceram. Int. 2014, 40, 15351-15370. [CrossRef]

16. Bouler, J.-M.; Pilet, P.; Gauthier, O.; Verron, E. Biphasic calcium phosphate ceramics for bone reconstruction: A review of biological response. Acta Biomater. 2017, 53, 1-12. [CrossRef]

17. Guex, A.G.; Puetzer, J.L.; Armgarth, A.; Littmann, E.; Stavrinidou, E.; Giannelis, E.P.; Malliaras, G.G.; Stevens, M.M. Highly porous scaffolds of PEDOT:PSS for bone tissue engineering. Acta Biomater. 2017, 62, 91-101. [CrossRef]

18. Woodard, J.R.; Hilldore, A.J.; Lan, S.K.; Park, C.J.; Morgan, A.W.; Eurell, J.C.; Clark, S.G.; Wheeler, M.B.; Jamison, R.D.; Johnson, A.J.W. The mechanical properties and osteoconductivity of hydroxyapatite bone scaffoFelds with multi-scale porosity. Biomaterials 2007, 28, 45-54. [CrossRef] [PubMed]

19. Rustom, L.E.; Boudou, T.; Lou, S.; Pignot-Paintrand, I.; Nemke, B.W.; Lu, Y.; Markel, M.D.; Picart, C.; Johnson, A.J.W. Micropore-induced capillarity enhances bone distribution in vivo in biphasic calcium phosphate scaffolds. Acta Biomater. 2016, 44, 144-154. [CrossRef] [PubMed]

20. Pecqueux, F.; Tancret, F.; Payraudeau, N.; Bouler, J.-M. Influence of microporosity and macroporosity on the mechanical properties of biphasic calcium phosphate bioceramics: Modelling and experiment. J. Eur. Ceram. Soc. 2010, 30, 819-829. [CrossRef]

21. Kim, D.-H.; Kim, K.-L.; Chun, H.-H.; Kim, T.-W.; Park, H.-C.; Yoon, S.-Y. In vitro biodegradable and mechanical performance of biphasic calcium phosphate porous scaffolds with unidirectional macro-pore structure. Ceram. Int. 2014, 40, 8293-8300. [CrossRef]

22. A Park, S.; Lee, S.J.; Seok, J.M.; Lee, J.H.; Kim, W.D.; Kwon, I.K. Fabrication of 3D Printed PCL/PEG Polyblend Scaffold Using Rapid Prototyping System for Bone Tissue Engineering Application. J. Bionic. Eng. 2018, 15, 435-442. [CrossRef] 
23. Almirall, A.; Larrecq, G.; Delgado, J.; Martínez, S.; Planell, J.; Ginebra, M.-P. Fabrication of low temperature macroporous hydroxyapatite scaffolds by foaming and hydrolysis of an $\alpha$-TCP paste. Biomaterials 2004, 25, 3671-3680. [CrossRef] [PubMed]

24. Smith, B.T.; Santoro, M.; Grosfeld, E.C.; Shah, S.R.; Beucken, J.J.V.D.; Jansen, J.A.; Mikos, A.G. Incorporation of fast dissolving glucose porogens into an injectable calcium phosphate cement for bone tissue engineering. Acta Biomater. 2017, 50, 68-77. [CrossRef]

25. Marques, C.F.; Perera, F.H.; Marote, A.; Ferreira, S.; Vieira, S.I.; Olhero, S.; Miranda, P.; Ferreira, J.M. Biphasic calcium phosphate scaffolds fabricated by direct write assembly: Mechanical, anti-microbial and osteoblastic properties. J. Eur. Ceram. Soc. 2017, 37, 359-368. [CrossRef]

26. Yuan, H.; Xing, K.; Hsu, H.-Y. Trinity of Three-Dimensional (3D) Scaffold, Vibration, and 3D Printing on Cell Culture Application: A Systematic Review and Indicating Future Direction. Bioengineering (Basel) 2018, 5, 57. [CrossRef]

27. Zhao, H.; Liang, W. A novel comby scaffold with improved mechanical strength for bonetissue engineering. Mater. Lett. 2017, 194, 220-223. [CrossRef]

28. Zhang, B.; Pei, X.; Song, P.; Sun, H.; Li, H.; Fan, Y.; Jiang, Q.; Zhou, C.; Zhang, X. Porous bioceramics produced by inkjet 3D printing: Effect of printing ink formulation on the ceramic macro and micro porous architectures control. Compos. Part B Eng. 2018, 155, 112-121. [CrossRef]

29. Kim, J.; Lee, J.; Yang, T.; Yoon, S.; Kim, B.; Park, H. TBA-based freeze/gel casting of porous hydroxyapatite scaffolds. Ceram. Int. 2011, 37, 2317-2322. [CrossRef]

30. Polo-Corrales, L.; Latorre-Esteves, M.; Ramirez-Vick, J.E. Scaffold Design for Bone Regeneration. J. Nanosci. Nanotechnol. 2014, 14, 15-56. [CrossRef] [PubMed]

31. Jia, Z.-Q.; Guo, Z.-X.; Chen, F.; Li, J.-J.; Zhao, L.; Zhang, L. Microstructure, phase compositions and in vitro evaluation of freeze casting hydroxyapatite-silica scaffolds. Ceram. Int. 2018, 44, 3636-3643. [CrossRef]

32. Yang, T.Y.; Lee, J.M.; Yoon, S.Y.; Park, H.C. Hydroxyapatite scaffolds processed using a TBA-based freeze-gel casting/polymer sponge technique. J. Mater. Sci. Mater. Med. 2010, 21, 1495-1502. [CrossRef]

33. Tang, Y.; Mao, M.; Qiu, S.; Zhao, K. Fabrication of porous ceramics with double-pore structure by stepwise freeze casting using water/diphenyl methane emulsion. Ceram. Int. 2018, 44, 1187-1192. [CrossRef]

34. Lopez-Heredia, M.A.; Sariibrahimoglu, K.; Yang, W.; Bohner, M.; Yamashita, D.; Kunstar, A.; van Apeldoorn, A.A.; Bronkhorst, E.M.; Lanao, R.P.F.; Leeuwenburgh, S.C.; et al. Influence of the pore generator on the evolution of the mechanical properties and the porosity and interconnectivity of a calcium phosphate cement. Acta Biomater. 2012, 8, 404-414. [CrossRef] [PubMed]

35. Kim, M.-S.; Kim, Y.-H.; Park, I.-H.; Min, Y.-K.; Seo, H.-S.; Lee, B.-T. PCL Infiltration into a BCP Scaffold Strut to Improve the Mechanical Strength while Retaining Other Properties. Kor. J. Mater. Res. 2010, 20, 331-337. [CrossRef]

36. Uth, N.; Muller, J.; Smucker, B.; Yousefi, A.-M. Validation of scaffold design optimization in bone tissue engineering: finite element modeling versus designed experiments. Biofabrication 2017, 9, 015023. [CrossRef]

37. Bruker. Bone mineral density (BMD) and tissue mineral density (TMD) calibration and measurement by micro-CT using Bruker-MicroCT CT-analyser. In HU and BMD calibration in Bruker-MicroCT CT-Anlayser; Method note; Bruker: Billerica, MA, USA, 2010.

38. Lee, J.H.; Park, T.G.; Park, H.S.; Lee, D.S.; Lee, Y.K.; Yoon, S.C.; Nam, J.-D. Thermal and mechanical characteristics of poly(L-lactic acid) nanocomposite scaffold. Biomaterials 2003, 24, 2773-2778. [CrossRef]

39. Tseng, T.-L.B.; Chilukuri, A.; Park, S.C.; Kwon, Y.J. Automated quality characterization of 3D printed bone scaffolds. J. Comput. Eng. 2014, 1, 194-201.

40. Boissard, C.; Bourban, P.-E.; Tami, A.; Alini, M.; Eglin, D. Nanohydroxyapatite/poly(ester urethane) scaffold for bone tissue engineering. Acta Biomater. 2009, 5, 3316-3327. [CrossRef]

41. Fu, Q.; Rahaman, M.N.; Dogan, F.; Bal, B.S. Freeze Casting of Porous Hydroxyapatite Scaffolds. II. Sintering, Microstructure, and Mechanical Behavior. J. Biomed. Mater. Res. 2008, 86B, 514-522. [CrossRef]

42. Deville, S.; Saiz, E.; Tomsia, A.P. Freeze casting of hydroxyapatite scaffolds for bone tissue engineering. Biomaterials 2006, 27, 5480-5489. [CrossRef] [PubMed]

(C) 2019 by the authors. Licensee MDPI, Basel, Switzerland. This article is an open access article distributed under the terms and conditions of the Creative Commons Attribution (CC BY) license (http://creativecommons.org/licenses/by/4.0/). 